\title{
ANALISIS TREND KEJADIAN KEKERINGAN DI SEBAGIAN WILAYAH PROPINSI D.I. YOGYAKARTA DAN DAMPAK EI-Nino TERHADAPNYA
}

\author{
Gilang Arya Dipayana ${ }^{1}$, Ahmad Cahyadi², Emilya Nurjani ${ }^{3}$ \\ 1,2Program Beasiswa Unggulan Biro Perencanaan dan Kerjasama Luar Negeri Kementrian \\ Pendidikan dan Kebudayaan Nasional Republik Indonesia \\ Pada Magister Perencanaan dan Pengelolaan Pesisir dan Daerah Aliran Sungai \\ Fakultas Geografi Universitas Gadjah Mada Yogyakarta \\ ${ }^{3}$ Staff Pengajar Jurusan Geografi Lingkungan Fakultas Geografi UGM \\ Email: 1aryadipayana@gmail.com, 2ahya.edelweiss@gmail.com,3n_emilya@yahoo.com
}

\begin{abstract}
INTISARI
Kekeringan adalah berkurangnya curah hujan yang cukup besar dan berlangsung lama yang dapat mempengaruhi kehidupan tanaman dan hewan pada suatu daerah dan akan menyebabkan berkurangnya cadangan air untuk keperluan hidup sehari-hari maupun kehidupan tanaman. Kondisi kekeringan menyebabkan kerugian yang besar bagi manusia termasuk di dalamnya kemungkinan terjadi langkanya sumberdaya air dan terancamnya ketahanan pangan. Bencana ini tidak dapat dihindari kejadiannya, namun dapat diminimalkan risikonya. Pengurangan risiko bencana kekeringan dapat dimulai dari kajian tentang trend kekeringan, pengaruh El-Nino terhadap kejadian kekeringan serta variabilitasnya ditinjau secara spasial. Kajian-kajian tersebut akan dapat digunakan untuk membantu dalam menyusun rencana pengurangan risiko bencana kekeringan di masa mendatang.

Penelitian ini bertujuan untuk (1) mengetahui trend kejadian kekeringan di sebagian wilayah Priopinsi D.I. Yogyakarta, dan (2) mengetahui pengaruh El-Nino pada kejadian kekeringan di wilayah kajian. Metode yang digunakan dalam penelitian ini adalah Standardized Precipitacion Index (SPI)-12 yang dikembangkan oleh McKee dkk, (1993). Hasil penelitian menunjukkan bahwa (1) Trend kejadian kekeringan cenderung menurun pada lima stasiun pengamatan sedangkan pada satu stasiun pengamatan mengalami kenaikan, dan (2) Kejadian El-Nino berpengaruh terhadap terjadinya nilai SPI yang rendah (kekeringan semakin tinggi).
\end{abstract}

Kata Kunci: Kekeringan, Trend kejadian, EL NINO, Standardized Precipitacion Index (SPI)

\section{PENDAhUluAN}

Perubabahan iklim telah menjadi permasalahan global, hal ini nampak dari diterimanya secara universal hasil konvensi PBB tentang perubahan iklim (UN Framework Convention on Climate Change, UNFCCC) pada konferensi tingkat tinggi (KTT) bumi tentang lingkungan dan pembangunan (UN Conference on Environment and Development, UNCED) di Rio de Janeiro, Brasil Tahun 1992 (Murdiyarso, 2005). Perubahan iklim telah menyebabkan banyak dampak negatif bagi kehidupan manusia (Ratag, 2008). Beberapa dampak perubahan iklim diantaranya adalah (1) Tren peningkatan curah hujan yang dilaporkan di Argentina (Viglizzo dkk,1995) serta di Australia dan Selandia Baru (Plummer dkk, 1999) dan (2) terjadinya trend penurunan curah hujan yang menyebabkan terjadinya kekeringan di Iran (Marsoudi dan Afrough, 2011), Afrika (Mason, 1996), dan Cina (Zhai et al. 1999).

Kekeringan meteorologi didefinisikan sebagai suatu kejadian yang berlangsung secara alami dan dapat terjadi secara berulang karena berkurangnya curah hujan dari kondisi normalnya (Rafiuddin dkk, 2011). Pengertian yang lain dikemukakan oleh US Weather Bureau dalam Ven Te Chow (1964) bahwa kekeringan adalah berkurangnya curah hujan yang cukup besar dan berlangsung lama yang dapat mempengaruhi kehidupan tanaman dan hewan pada suatu daerah dan akan menyebabkan berkurangnya cadangan air untuk keperluan hidup seharihari maupun kehidupan tanaman. Pengertian serupa dikemukakan oleh Dickerson dan Dethier (1970) bahwa kekeringan adalah penurunan jumlah curah hujan yang signifikan dari kondisi normal dalam waktu yang cukup lama dengan cakupan yang cukup luas.

Kajian mengenai kekeringan menjadi sangat penting karena kekeringan telah menyebabkan banyak kerugian bagi manusia. Setidaknya terdapat lima (5) alasan yang menjadikan kajian terhadap kekeringan menjadi begitu penting, yaitu; (a) Kekeringan adalah suatu kejadian yang tidak dapat dicegah, namun kajian tentangnya dapat digunakan untuk merencanakan upaya-upaya untuk menghadapinya sehingga risiko yang mungkin timbul akan semakin kecil, (b) Ketepatan prediksi tentang kondisi kekeringan pada masa mendatang akan menentukan keefektifan program yang direncanakan, sehingga kajian tentang metode prediksi kekeringan harus terus dicoba, (c) 
Kesiapsiagaan yang rendah akan menyebabkan dampak kekeringan menjadi semakin parah, (d) Hasil kajian prediksi kekeringan akan menentukan kebijakan yang akan diambil pada masa mendatang, dan (e) Kekeringan tidak hanya akan berdampak pada lokasi yang mengalami kekeringan, namun akan meluas karena terkait dengan sektor ekonomi dan pangan serta ketersediaan sumberdaya yang dibutuhkan banyak orang (Rafiuddin dkk, 2011). Penelitian ini bertujuan untuk (1) mengetahui trend kejadian kekeringan di sebagian wilayah Priopinsi D.I. Yogyakarta, dan (2) mengetahui pengaruh EL NINO pada kejadian kekeringan di wilayah kajian.

\section{METODE PENELITIAN}

Identifikasi kekeringan dilakukan dengan menggunakan Standardized Precipitacion Index. Standardized Precipitacion Index (SPI) merupakan suatu metode yang dikembangkan oleh McKee dkk, (1993) untuk mengukur kekurangan curah hujan dalam beberapa skala waktu $(1,3,6,12,24$, 48 bulan). Ini memungkinkan metode SPI untuk mengukur persediaan air dalam jangka waktu pendek, seperti lengas tanah yang penting untuk produksi pertanian, serta dapat digunakan untuk keperluan sumber air untuk jangka panjang, seperti persediaan airtanah, dan tinggi muka air. Variabel yang digunakan dalam perhitungan SPI ini adalah curah hujan bulanan. Perhitungan SPI berdasarkan pada data curah hujan dalam jangka waktu yang lama, yang kemudian menggunakan distribusi Gamma lalu diubah menjadi distribusi normal.

Nilai SPI ditentukan dengan menggunakan software Standardized Precipitacion Index Calculator yang dikeluarkan oleh National Drought mitigation Center, University of Nebraska-Lincoln. Jika diruntutkan secara manual, maka perhitungan SPI yang digunakan adalah sebagai berikut:

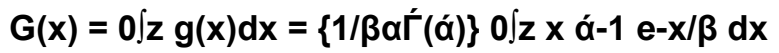
berikut :

Nilai $\alpha$ dan $\beta$ diestimasi untuk setiap stasiun hujan dengan menggunakan rumus sebagai

Atau

$$
\begin{gathered}
\alpha=1 / 4 A\{1+\sqrt{ } 1+(4 A / 3)\} \\
A=\ln (\dot{X})-\{\Sigma \ln (x) / n\}
\end{gathered}
$$

$$
\alpha=\dot{X} 2 / s 2 \text { dan } \beta=\dot{X} / \alpha \quad \text { Untuk } x>0
$$

Untuk $\mathrm{x}=0$ maka nilai $\mathrm{G}(\mathrm{x})$ menjadi :

$$
H(x)=q+(1-q) \cdot G(x)
$$

Dengan $\mathrm{q}=$ jumlah kejadian hujan $=0(\mathrm{~m}) / \mathrm{jumlah}$ data $(\mathrm{n})$

Nilai SPI merupakan transformasi dari distribusi gamma $(G(x))$ menjadi standar normal dengan rata-rata (mean) 0 dan perbedaan 1 , atau menggunakan rumusan di bawah ini :

$$
\begin{aligned}
& Z=S P I=-\left\{t-\frac{c_{0}+c_{1} t+c_{2} t^{i}}{1+d_{1} t+d_{2} t^{i}+d_{3} t^{5}}\right\} \\
& Z=S P I=+\left\{t-\frac{c_{0}+c_{1} t+c_{2} t^{i}}{1+d_{1} t+d_{2} t^{i}+d_{3} t^{3}}\right\} \\
& \text { untuk : } 0,5<H(x)<1,0
\end{aligned}
$$

Dimana,

$$
\begin{gathered}
\mathbf{t}=\sqrt{ } \ln \{1 /(\mathbf{H}(\mathbf{x})) 2\} \text { untuk: } 0<H(x)<0,5 \\
\mathbf{t}=\sqrt{ } \ln \{\mathbf{1} /(\mathbf{1}, \mathbf{0}-\mathbf{H}(\mathbf{x})) \mathbf{2}\} \text { untuk: } 0,5<H(x)<1,0
\end{gathered}
$$

Trend kejadian kekeringan dilakukan dengan menganalisis nilai SPI bulan yang sama dari tahun 1984-2007. Nilai SPI pada bulan tertentu pada masing-masing tahun diplot pada scatter charts untuk melihat distribusinya dan ditentukan trendline dari distribusinya. Berdasarkan trendline tersebut, maka akan diperoleh pola dari nilai SPI yang kemudian dapat digunakan untuk menganalisis trend kejadian kekeringan.

Pengaruh EI-Nino terhadap kekeringan dianalisis dengan menghubungkan nilai SPI pada kondisi saat terjadi El-Nino dan pada saat tidak terjadi atau lemah. Analisis yang dilakukan pada langkah tersebut adalah untuk mengetahui apakah pada saat terjadi El-Nino nilai SPI menunjukkan terjadinya kekeringan. Selain itu dapat pula dilakukan analisis tingkat kekeringan yang terjadi berdasarkan nilai SPI. Data kejadian El-Nino menggunakan data multivariate ENSO Index (MEI) yang diunduh dari http://www.esrl.noaa.gov/psd/people/klaus.wolter/MEl/table.htm. 
Tabel 1. Nilai SPI (Standardized Precipitacion Index)

\begin{tabular}{|l|l|}
\hline \multicolumn{1}{|c|}{ Nilai SPI } & \multicolumn{1}{c|}{ Kondisi } \\
\hline$>2$ & Ekstrim Basah \\
\hline$>1,5$ sampai 2 & Sangat Basah \\
\hline$>1$ sampai 1,5 & Agak Basah \\
\hline 1 sampai -1 & Normal \\
\hline$<-1$ samapai $-1,5$ & Agak kering \\
\hline$<-1,5$ sampai -2 & Sangat Kering \\
\hline$<-2$ & Ekstrim Kering \\
\hline
\end{tabular}

\section{HASIL DAN PEMBAHASAN}

Hasil analisis trend SPI pada setiap bulan menunjukkan bahwa dari enam stasiun pengamatan hujan terdapat lima stasiun yang menunjukkan trend kenaikan nilai SPI yakni Bronggang, Dolo, Gandok, Jangkang dan Pakem, sedangkan satu stasiun yakni Stasiun Sambiroto. Nilai SPI yang cenderung naik berarti bahwa kondisinya semakin basah, atau dapat pula diartikan bahwa trend kejadian kekeringan semakin menurun. Kondisi ini mengindikasikan bahwa terjadi jumlah hujan yang semakin banyak di Wilayah Propinsi D.I. Yogyakarta.

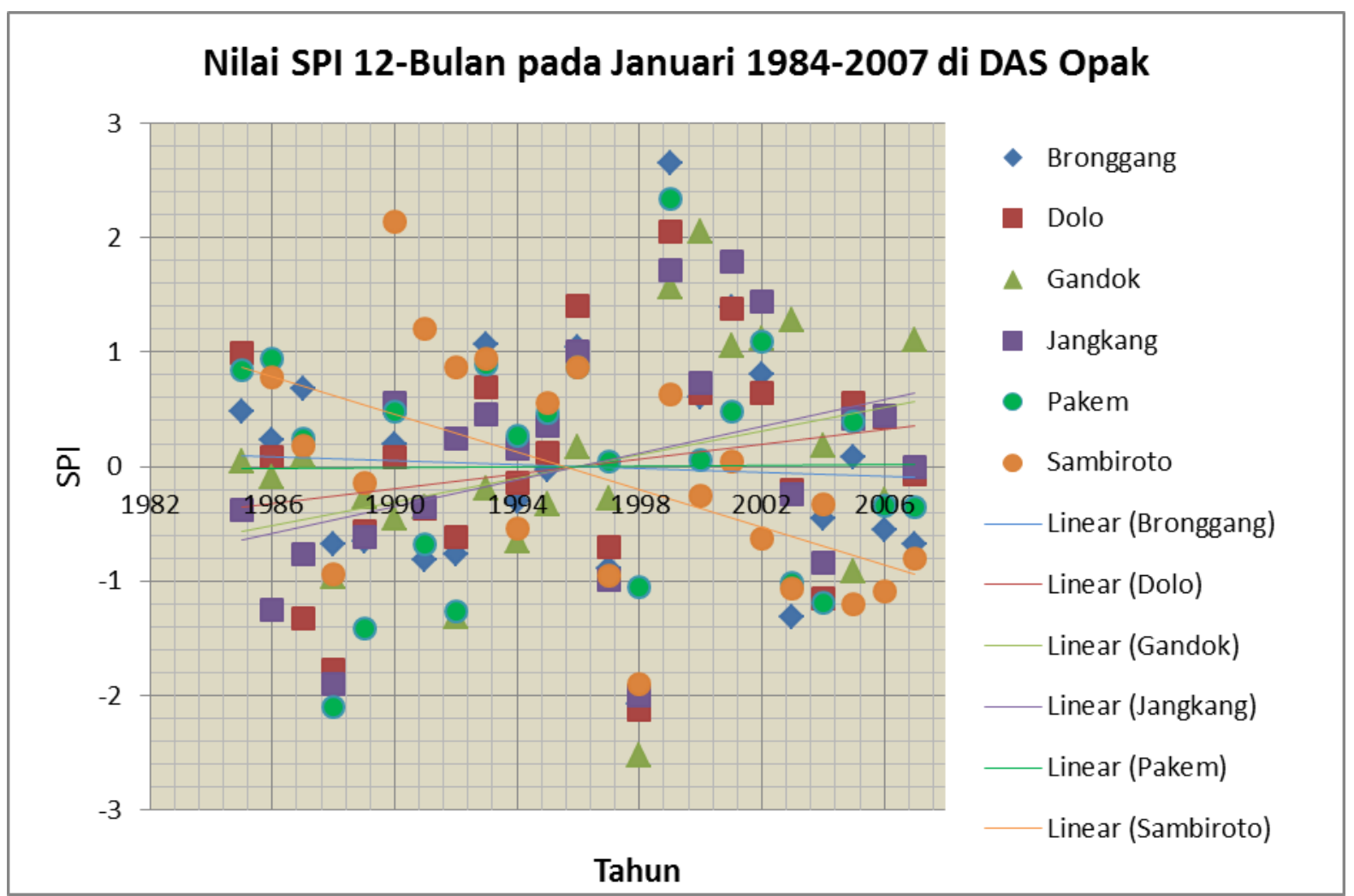

Gambar 1. Trend Nilai SPI di Beberapa Stasiun Hujan di D.I. Yogyakarta pada Bulan Januari 


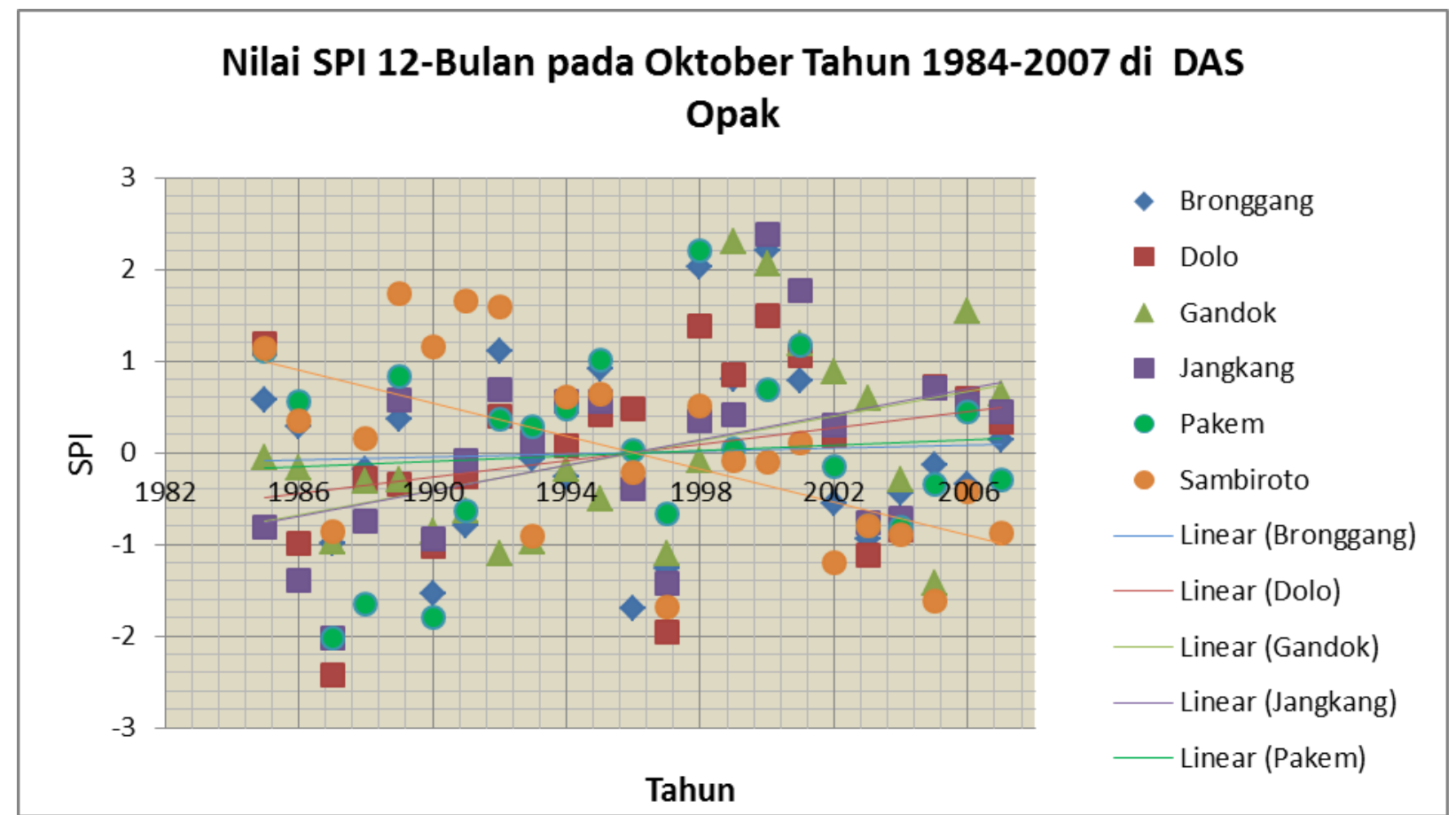

Gambar 2. Trend Nilai SPI di Beberapa Stasiun Hujan di D.I. Yogyakarta pada Bulan Oktober

Hasil analisis nilai SPI pada beberapa kejadian El-Nino menunjukkan bahwa nilai SPI sangat rendah. Tahun 1986-1987 ketika terjadi El-Nino selama 10 Bulan dengan Southern Oscillation Index (SOI) -15 maka hampir semua stasiun menunjukkan nilai SPI <-2. Kejadian yang lain misalnya pada Tahun 1997 - 1998 kejadian El-Nino selama 14 bulan (Bulan Maret 1997-April 1998) dengan SOI 18, maka nampak bahwa pada hampir semua stasiun memiliki nilai <-1.

Berdasarkan hal tersebut, maka analisis trend kejadian kekeringan sebaiknya juga memperhatikan kejadian El-Nino. Bahkan, mungkin diperlukan analisis interkoneksi antara beberapa kejadian yang mungkin dapat menyebabkan terjadinya anomali seperti El-Nino, La-Nina, Dipole Mode Index (DMI), Madden Julian Oscillation (MJO) dan Monsun. Berdasarkan analisis-analisis interkoneksi tersebut, maka akan didapat analisis yang komplek dan prediksi yang lebih baik pada masa mendatang.

\section{KESIMPULAN}

Kesimpulan dari penelitian ini adalah:

1. Trend kejadian kekeringan cenderung menurun pada lima stasiun pengamatan sedangkan pada satu stasiun pengamatan mengalami kenaikan, dan

2. Kejadian EL NINO berpengaruh terhadap terjadinya nilai SPI yang rendah (kekeringan semakin tinggi).

\section{UCAPAN TERIMA KASIH}

Terimakasih kami ucapakan kepada program BEASISWA UNGULAN Biro Perencanaan dan Kerjasama Luar Negeri (BPKLN) Kementrian Pendidikan dan Kebudayaan Nasional Republik Indonesia yang telah mendukung sepenuhnya penelitian dan keikutsertaan kami dalam seminar di Universitas Muhammadiyah Surakarta ini. Besar harapan kami agar program ini terus berjalan untuk mewujudkan Indonesia yang maju, makmur, sejahtera dan mandiri dengan sumberdaya manusia yang unggul.

\section{DAFTAR PUSTAKA}

Dickerson, W.H., dan Dethier, B.E. 1970. Drought Frequency in The Northeastern United States. Morgantown: West Virginia University.

Mason, S.J. 1996. Climatic Change Over the Lowveld of South Africa. Climatic Change, Vol. 32. Hal: 35-54. 
Masoudi, M., Afrough, E. 2011. Analyzing Trends of Precipitation for Humid, Normal and Drought Classes using Standardized Precipitation Index (SPI), A Case of Study: Fars Province, Iran. International Journal of AgriScience Vol. 1(2). Hal: 58-69.

McKee, T. B., N. J. Doesken, and J. Kleist. 1993. The Relationship of Drought Frequency and Duration to Time Scales. Preprints, 8th Conference on Applied Climatology, 17-22 January, Anaheim, CA. Hal: 179-184.

Murdiyarso, Daniel. 2005. Sepuluh Tahun Perjalanan Negosiasi Konvensi Perubahan Iklim, Cetakan Kedua. Jakarta: Penerbit buku Kompas.

Plummer N, Salinger MJ, Nicholls N, et al. (1999) Changes in Climate Extremes over The Australian Region and New Zealand During The Twentieth Century. Climatic Change, Vol. 42. Hal:183202.

Rafiuddin, M., Dash, B.K., Khanam, F., Islam, M.N. 2011. Diagnosis of Drought in Bangladesh using Standardized Precipitation Index. International Conference on Environment Science and Engineering vol.8. Singapore: IACSIT Press.

Ratag, Mezak Arnold. 2008. Perubahan Iklim: Isu-Isu Ilmiah. Jakarta: Badan Meteorologi dan Geofisika.

Ven Te Chow. 1964. Handbook of Applied Hydrology: A Compendium of Water-resources Technology. New York: McGraw-Hill.

Viglizzo, E.F., Roberto, Z.E., Filippin, M.C., Pordomingo, A.J. 1995. Climate Variability and Agroecological Change in The Central Pampas of Argentina. Agriculture, Ecosystems \& Environment, Vol. 55. Hal:7-16.

Zhai, P.M., Sun, A.J., Ren, F.M., Liu, X.L., Gao, B., Zhang, Q. 1999. Changes of Climate Extremes in China. Climatic Change, Vol. 42. Hal: 203-218. 